\title{
PROSPECT+SAIL: 15 Years of Use for Land Surface Characterization
}

\author{
S. Jacquemoud \\ IPGP / Université Paris 7 \\ 4 place Jussieu \\ 75252 Paris Cedex 05, France \\ jacquemoud@ipgp.jussieu.fr \\ P.J. Zarco-Tejada \\ Instituto de Agricultura Sostenible \\ Alameda del Obispo \\ 14004 Córdoba, Spain \\ pzarco@ias.csic.es
}

\author{
W. Verhoef \\ National Aerospace Laboratory \\ Voorsterweg 31 \\ 8316 PR Marknesse, The Netherlands \\ verhoef@nlr.nl \\ G.P. Asner \\ Carnegie Institution \\ 260 Panama Street \\ Stanford, CA 94305, USA \\ gasner@globalecology.stanford.edu \\ S.L. Ustin \\ CSTARS / University of California \\ The Barn \\ Davis, CA 95616, USA \\ slustin@ucdavis.edu
}

\author{
F. Baret \\ INRA / Unité Climat, Sol et Environnement \\ Domaine St Paul, Site Agroparc \\ 84914 Avignon Cedex 09, France \\ baret@avignon.inra.fr \\ C. François \\ Ecologie, Systématique et Evolution \\ Université Paris-Sud \\ 91405 Orsay Cedex, France \\ christophe.francois@ese.u-psud.fr
}

\begin{abstract}
The combined PROSPECT leaf optical properties model and SAIL canopy bidirectional reflectance model, i.e. PROSAIL, has been used for about fifteen years to increase our understanding of plant canopy spectral and bidirectional reflectance in the solar domain and to develop new methods of vegetation biophysical properties retrieval. It links the spectral variation of canopy reflectance with its directional variation. This link is the key to simultaneously estimate biophysical/structural canopy variables for applications in agriculture, plant physiology, and forestry at different scales. PROSPECT and SAIL are still evolving: they have undergone recent improvements both at the leaf and the plant levels and became one of the most popular radiative transfer tools in these domains due to their ease of use, their robustness, and because they have been validated by many lab/field/space experiments over the years. This paper is intended to review this subject, which has been extensively researched in optical remote sensing.
\end{abstract}

Keywords-canopy spectral and directional reflectance; models; PROSPECT; SAIL; PROSAIL;

\section{INTRODUCTION}

From the beginning of optical remote sensing, radiative transfer models served to help understand how light is intercepted by plant canopies and to interpret the reflectance in terms of vegetation biophysical characteristics. Since they describe more or less precisely the two main physical principles involved in such a medium, i.e. absorption and scattering, one is apt to believe that they can be very useful in tasks such as designing vegetation indices, performing sensitivity analyses, and building up inversion procedures destined to accurately retrieve these characteristics. Among all the codes published in the literature during the last two decades
[1], the SAIL canopy bidirectional reflectance model and the PROSPECT leaf optical properties model are the most popular codes and are looked on as standards. Their combination in PROSAIL about fifteen years ago linked the spectral variation of canopy reflectance, which is mainly related to leaf biochemical contents such as total chlorophyll, water, or dry matter, with its directional variation, which is classically related to the canopy architecture, i.e. leaf area index, leaf angle distribution, hot spot parameter or clumping effect. This link is essential to simultaneously estimate these variables. It partly explains the success of PROSAIL.

\section{MODEL OVERVIEW}

Now in widespread use in the remote sensing community, SAIL (Scattering Arbitrary Inclined Leaves) was one of the earliest canopy reflectance models [2-3]. It was an extension to the 1-D model developed by [4] and solved the scattering and extinction of four upward/downward fluxes within the canopy to predict the bidirectional reflectance of homogeneous plant canopies. SAIL has given rise to several versions: SAILH which includes the hot spot parameter after a formalism by [5], FLSAIL [6] and FluorSAIL [7] which take into account the chlorophyll fluorescence effects on reflectance, GeoSAIL which is the combination of SAIL and a geometric model to simulate discontinuous canopies [8], and recently 4SAIL which is a numerically robust and speed-optimized version of the model [9]. SAIL was successfully compared to other 1-D and $3-\mathrm{D}$ codes in the frame of the RAMI (RAdiation transfer Model Intercomparison) organized by the JRC in Ispra, Italy.

At the leaf level, PROSPECT pioneered the simulation of hemispherical reflectance and transmittance of various green monocots and dicots, and senescent leaves, over the solar 
spectrum [10]. The latter are represented as one or several absorbing plates with rough surfaces giving rise to isotropic diffusion. The model uses two classes of input variables: the leaf structure parameter $\mathrm{N}$, number of compact layers specifying the average number of air/cell walls interfaces within the mesophyll, and the leaf biochemical content which has varied over the years [11-13]. The directional optical properties have been recently introduced by [14] and a new version including chlorophyll $a$ fluorescence is underway [15].

Where other models have been developed, generally they have received inadequate validation and comparison with existing ones, either due to lack of resources or limited access. The large diffusion of PROSPECT and SAIL is attributed to their simplicity, accuracy, and above all their availability to the research community.

\section{COUPLING OF PROSPECT AND SAIL}

The first model inversions of SAIL performed by [16] allowed estimates of canopy architecture (LAI, leaf angle distribution) by using bidirectional reflectance measurements acquired in a given waveband. Currently, only POLDER and MISR have the capability to produce such data. Most sensors measure the Earth radiance in several wavebands and one direction. However, multispectral or hyperspectral data cannot be inverted by SAIL alone because the increase in the number of wavebands rapidly leads to an under-determined system. Since leaf reflectance, leaf transmittance, and soil reflectance are three wavelength dependent input variables of SAIL, the implementation of this model to predict biophysical variables from canopy reflectance spectra at given solar and viewing angles in a defined relative azimuth plane requires at least three times as many variables as wavelengths. As a consequence, the inversion of SAIL is impracticable unless several viewing angles are available. In order to reduce the dimensionality of the inverse problem and to assess the canopy biochemistry, SAILH was coupled with PROSPECT early in the 90's to give PROSAIL. The main input variables of the latter are shown in Table I. This was the beginning of a long series of published literature.

TABLE I. MAIN VARIABLES OF PROSAIL

\begin{tabular}{|l|l|l|}
\hline \multicolumn{1}{|c|}{ Symbol } & \multicolumn{1}{c|}{ Quantity } & \multicolumn{1}{c|}{ Unit } \\
\hline $\mathrm{N}$ & Leaf structure parameter & - \\
\hline $\mathrm{C}_{\mathrm{ab}}$ & Chlorophyll a+b concentration & $\mu \mathrm{g} \mathrm{cm}^{-2}$ \\
\hline $\mathrm{C}_{\mathrm{w}}$ & Equivalent water thickness & $\mathrm{cm}^{-2}$ \\
\hline $\mathrm{C}_{\mathrm{m}}$ & Dry matter content & $\mathrm{g} \mathrm{cm}^{-2}$ \\
\hline $\mathrm{C}_{\mathrm{b}}$ & Brown pigments content & - \\
\hline LAI & Leaf Area Index & - \\
\hline LIDF & Leaf Inclination Distribution Function & - \\
\hline $\mathrm{S}_{\mathrm{l}}$ & Hot spot parameter & - \\
\hline$\rho_{\mathrm{s}}(\lambda)$ & Soil reflectance assumed Lambertian & - \\
\hline $\mathrm{SKYL}(\lambda)$ & Ratio of diffuse to total incident radiation & - \\
\hline Sza & Solar zenith angle & $\mathrm{deg}$ \\
\hline vza & Viewing zenith angle & $\mathrm{deg}$ \\
\hline raa & Relative azimuth angle & $\mathrm{deg}$ \\
\hline
\end{tabular}

It should be mentioned that PROSPECT has also been integrated into other canopy reflectance models: FCR [17], NADI [13, 18], DART [19], GeoSAIL [20-23], FLIM [24], SPRINT [25], and FLIGHT [23].

\section{SIMULATIONS WITH PROSAIL}

Models can be run in direct mode. One of the first applications of PROSAIL was the study of the red edge [26]. Spectral shifts in this wavelength domain were shown to be mainly produced by variations in $\mathrm{C}_{\mathrm{ab}}$ and $\mathrm{LAI}$ and the position of the inflexion point to be almost insensitive to soil substrate and atmospheric conditions. By successively changing the input variables, [27] performed a rough sensitivity analysis which revealed that $\mathrm{N}$ slightly changed the canopy reflectance and that LAI and the average leaf angle of the LIDF produced quite similar effects in the model. As a result, the separate quantification of these two variables is problematic. The canopy reflectance sensitivity to leaf optical properties was evaluated by [28] who showed that the leaf biochemical signal could be enhanced at the canopy level by a factor of two. Finally, [29] and [30] compared modeled and measured spectra to monitor changes in sugar beet crop spectral reflectance caused by diurnal water stress.

Several vegetation indexes have been also screened or designed using PROSAIL: for instance, the relationship between the Weighted Difference Vegetation Index and the LAI was verified for varying external factors [31]. Eight vegetation indexes were compared with a neural network approach to determine the canopy gap fraction [32]. References $[24,33]$ simulated canopy reflectance spectra in the VIS-NIR to test the Transformed Chlorophyll Absorption in Reflectance Index / Optimized Soil-Adjusted Vegetation Index ratio which was supposed to be sensitive to low chlorophyll values and resistant to vegetation non-photosynthetic materials. In the SWIR, the fuel moisture content at canopy level was related to the Simple Ratio Water Index [34] and to the Normalized Difference Water Index [20]. These two studies pointed out the difficulty of accurate estimations using a semi-empirical approach and demonstrated the need for a coupled leaf-canopy model to successfully estimate $\mathrm{C}_{\mathrm{w}}$ at canopy level.

Model simulations can also help quantify the contribution of canopy input variables one-by-one to canopy reflectance. Recent studies based on statistical methods like the Design Of Experiments for Simulation [35-36] or the Extended Fourier Amplitude Sensitivity Test [20] made it possible to perform complete sensitivity analyses of PROSAIL. By quantifying the contribution of each of the input variables to the model outputs, as well as their interactions, such analyses proved informative about the optimal wavebands and viewing directions to retrieve canopy biophysical characteristics. For instance, the canopy reflectance turned out to be the most sensitive to $\mathrm{C}_{\mathrm{ab}}$ in the backward direction where shadows are reduced, to LAI in the forward direction where photons have interacted twice with the plants and to leaf orientation at nadir where the soil background is visible [35-36]. The spectral domain where canopy reflectance is sensitive to water or to the specific leaf area was also found this way [20]. A further integrated model including the soil BRDF and the atmosphere showed how topof-atmosphere hyperspectral radiances under multiple view angles could be predicted [37]. This model was used to assess the performance of several mission concepts by sensitivity analysis. Finally, one can mention the availability of FluorMODgui, a Graphic User Interface software package [38] developed within the frame of the FluorMOD project funded 
by the European Space Agency and which enables simulation of leaf and canopy reflectance with or without the effects of chlorophyll fluorescence [7].

\section{INVERSION OF PROSAIL}

The inverse problem is crucial in remote sensing where the radiometric signal has to be interpreted in terms of canopy biophysical characteristics. Although they represent a majority of approaches to retrieve these characteristics, we will omit here any reference to vegetation indices. One can attack the inverse problem of PROSAIL in three ways: iterative methods, look-up tables, and neural networks. The first two methods share the minimization of the distance between simulated and measured reflectance, while the last one focuses on the biophysical variables.

The first attempt to iteratively estimate $\mathrm{C}_{\mathrm{ab}}, \mathrm{C}_{\mathrm{w}}$ and LAI from high resolution reflectance spectra acquired at nadir in the solar domain was made on sugar beet crops [39]. While retrieving the main canopy variables using AVIRIS, CASI, and TM sensors, unstable inversions were observed due to interferences between the LAI and the LIDF in the reflectance signal, but the determination of total chlorophyll $\left(\mathrm{C}_{\mathrm{ab}} \times \mathrm{LAI}\right)$ or water $\left(\mathrm{C}_{\mathrm{w}} \times \mathrm{LAI}\right)$ contents seemed to be attainable [13, 27, 40, 41]. A limited number of wavebands and view angles should however permit a better separation of the variables [42-44]. The main problem of iterative inversion methods is a prohibitive computation time and the risk of converging on a local minimum.

The look-up table is conceptually a simple technique to overcome the above-mentioned limitations. It consists of generating an output table with PROSAIL for a discrete set of input variables covering their natural range of variation. This table is then used to find the solution to the problem, i.e., the sets of input variables which provide the closest estimate of reflectance. This method permited estimation of $\mathrm{C}_{\mathrm{ab}}$, LAI, fAPAR, and fCover [21, 45-47].

As an alternative, neural networks have lately become a standard method to operationally invert PROSAIL. The input variables are drawn at random within given distribution laws to produce a learning data set to train the neural network and a test data set to evaluate its performance. This approach has been successfully applied to VEGETATION [48], MERIS [49] and POLDER [50] to determine the LAI or the gap fraction.

The three methods were adapted to account for prior information and evaluated over synthetic canopy reflectances [51]. Results demonstrated a significant improvement of canopy variables retrieval when using such information.

\section{CONCLUSION}

As illustrated in this paper, plant canopy reflectance models have become essential tools for the analysis of optical remote sensing data, providing meaningful links between radiometry for both ecology and precision agriculture. The coupling of PROSPECT with SAIL made it possible to physically interpret multispectral or hyperspectral images in terms of leaf biochemical content, but also, when the requirements are fitted, in terms of canopy architecture. When run in direct mode,
PROSAIL provides a means to generate databases and test new spectral indexes, to perform sensitivity analyses which will allow to better design forthcoming sensors devoted to specific applications. When embedded in an inversion procedure, it turns into a powerful tool to derive new products. The first maps of chlorophyll or water content appeared just a few years ago. In the future, terrestrial ecosystems could be monitored in a totally different way when we are able to explore the main photosynthetic pigments separately or leaf structural properties.

\section{ACKNOWLEDGMENT}

We are grateful to the space agencies (CNES, ESA, EU, NASA, NLR) and national remote sensing programs (PNTS, CalSpace) for funding provided during the last 15 years.

\section{REFERENCES}

[1] S. Liang, Quantitative remote sensing of land surfaces. WileyInterscience, 2003, 560 pp.

[2] W. Verhoef, "Light scattering by leaf layers with application to canopy reflectance modeling: the SAIL model," Remote Sens. Environ., vol. 16, pp. 125-141, 1984.

[3] W. Verhoef, "Earth observation modeling based on layer scattering matrices," Remote Sens. Environ., vol. 17, pp. 165-178, 1985.

[4] G.H. Suits, "The calculation of the directional reflectance of a vegetative canopy," Remote Sens. Environ., vol. 2, pp. 117-125, 1972.

[5] A. Kuusk, "The hot spot effect in plant canopy reflectance," in PhotonVegetation Interactions. Applications in Optical Remote Sensing and Plant Ecology, R.B. Myneni and J. Ross, Eds. Berlin: Springer Verlag, pp. 139-159, 1991.

[6] A. Rosema, W. Verhoef, J. Schroote, and J.F.H. Snel, "Simulating fluorescence light-canopy interaction in support of laser-induced fluorescence measurements," Remote Sens. Environ., vol. 37, pp. 117130,1991 .

[7] J. Miller et al., "Development of a Vegetation Fluorescence Canopy Model", ESTEC Contract No. 16365/02/NL/FF, 2005, 138 pp.

[8] K.F. Huemmrich, "The GeoSail model: a simple addition to the SAIL model to describe discontinuous canopy reflectance," Remote Sens. Environ., vol. 75, pp. 423-431, 2001.

[9] W. Verhoef, L. Jia, Q. Xiao, and Z. Su, "Unified optical-thermal fourstream radiative transfer theory for heterogenous vegetation canopies," unpublished.

[10] S. Jacquemoud, and F. Baret, "PROSPECT: a model of leaf optical properties spectra," Remote Sens. Environ., vol. 34, pp. 75-91, 1990.

[11] T. Fourty, F. Baret, S. Jacquemoud, G. Schmuck, and J. Verdebout, "Optical properties of dry plant leaves with explicit description of their biochemical composition: direct and inverse problems," Remote Sens. Environ., vol. 56, pp. 104-117, 1996.

[12] S. Jacquemoud, S.L. Ustin, J. Verdebout, G. Schmuck, G. Andreoli, and B. Hosgood, "Estimating leaf biochemistry using the PROSPECT leaf optical properties model," Remote Sens. Environ., vol. 56, pp. 194-202, 1996.

[13] S. Jacquemoud, C. Bacour, H. Poilvé, and J.P. Frangi, "Comparison of four radiative transfer models to simulate plant canopies reflectance Direct and inverse mode," Remote Sens. Environ., vol. 74, pp. 471-481, 2000 .

[14] L. Bousquet, S. Lachérade, S. Jacquemoud, and I. Moya, "Leaf BRDF measurement and model for specular and diffuse component differentiation," Remote Sens. Environ., vol. 98, pp. 201-211, 2005.

[15] R. Pedrós, Y. Goulas, S. Jacquemoud, J. Louis, I. Moya, "A new leaf fluorescence model. Part 1: Fluorescence excitation \& Part 2: fluorescence emission," unpublished.

[16] N.S. Goel, "Inversion of canopy reflectance models for estimation of biophysical parameters from reflectance data," in Theory and 
Applications of Optical Remote Sensing, G. Asrar, Ed. Wiley Interscience, pp. 205-251, 1989.

[17] A. Kuusk, "A multispectral canopy reflectance model," Remote Sens. Environ., vol. 50, pp. 75-82, 1994.

[18] P. Ceccato, N. Gobron, S. Flasse, B. Pinty, and S. Tarantola, "Designing a spectral index to estimate vegetation water content from remote sensing data: Part 1. Theoretical approach," Remote Sens. Environ.. vol. 82, pp. 188-197, 2002.

[19] V. Demarez, and J.P. Gastellu-Etchegorry, "A modeling approach for studying forest chlorophyll content," Remote Sens. Environ., vol. 71, pp. 226-238, 2000.

[20] P. Bowyer, and F.M. Danson, "Sensitivity of spectral reflectance to variation in live fuel moisture content at leaf and canopy level," Remote Sens. Environ., vol. 92, pp. 297-308, 2004.

[21] W. Verhoef, and H. Bach, "Remote sensing data assimilation using coupled radiative transfer models", Phys. Chem. Earth, vol. 28, pp. 3-13, 2003.

[22] W. Verhoef, and H. Bach, "Simulation of hyperspectral and directional radiance images using coupled biophysical and atmospheric radiative transfer models," Remote Sens. Environ., vol. 87, pp. 23-41.

[23] B. Koetz, M. Schaepman, F. Morsdorf, P. Bowyer, K. Itten, and B. Allgöwer, "Radiative transfer modeling within heterogeneous canopy for estimation of forest fire fuel properties," Remote Sens. Environ., vol. 92, pp. 332-344, 2004.

[24] P.J. Zarco-Tejada, J.R. Miller, A. Morales, A. Berjona, and J. Agüerad, "Hyperspectral indices and model simulation for chlorophyll estimation in open-canopy tree crops," Remote Sens. Environ., vol. 90, pp. 463476, 2004.

[25] P.J. Zarco-Tejada et al., "Needle chlorophyll content estimation through model inversion using hyperspectral data from Boreal conifer forest canopies," Remote Sens. Environ., vol. 89, pp. 1989-1999, 2004.

[26] F. Baret, S. Jacquemoud, G. Guyot, and C. Leprieur, "Modeled analysis of the biophysical nature of spectral shifts and comparison with information content of broad bands", Remote Sens. Environ., vol. 41, pp. 133-142, 1992.

[27] S. Jacquemoud, "Inversion of the PROSPECT+SAIL canopy reflectance model from AVIRIS equivalent spectra: theoretical study," Remote Sens. Environ., vol. 44, pp. 281-292, 1993.

[28] F. Baret, V.C. Vanderbilt, M.D. Steven, and S. Jacquemoud, "Use of spectral analogy to evaluate canopy reflectance sensitivity to leaf optical properties," Remote Sens. Environ., vol. 48, pp. 253-260, 1994.

[29] B. Andrieu, F. Baret, S. Jacquemoud, T. Malthus, and M.D. Steven, "Evaluation of an improved version of the SAIL model to simulate bidirectional reflectance of sugar beet canopies," Remote Sens. Environ., vol. 60, pp. 247-267, 1997.

[30] F.M. Danson, and Y.Y. Aldakheel, "Diurnal water stress in sugar beet: spectral reflectance measurements and modelling," Agronomie, vol. 20, pp. 31-39, 2000 .

[31] J.G.P.W. Clevers, and W. Verhoef, "LAI estimation by means of the WDVI: a sensitivity analysis with a combined PROSPECT-SAIL model," Remote Sens. Rev., vol. 7, pp. 43-64, 1993.

[32] F. Baret, J.G.P.W. Clevers, and M.D. Steven, "The robustness of canopy gap fraction estimates from red and near-infrared reflectances: A comparison of approaches", Remote Sens. Environ., vol. 54, pp. 141$151,1995$.

[33] D. Haboudane, J.R. Miller, N. Tremblay, P.J. Zarco-Tejada, and L. Dextraze, "Integrated narrow-band vegetation indices for prediction of crop chlorophyll content for application to precision agriculture," Remote Sens. Environ. vol. 81, pp. 416-426, 2002.

[34] P.J. Zarco-Tejada, C.A. Rueda, and S.L. Ustin, "Water content estimation in vegetation with MODIS reflectance data and model inversion methods," Remote Sens. Environ., vol. 85, pp. 109-124, 2003.

[35] C. Bacour, S. Jacquemoud, P. Vogt, B. Hosgood, G. Andreoli, and J.P. Frangi, "Optimal sampling configurations for the estimation of canopy properties from BRDF data acquired with the EGO/JRC," in Proc. $8^{\text {th }}$ Int. Symp. Physical Measurements \& Signatures in Remote Sensing, Aussois (France), 8-12 January 2001, CNES, pp. 481-486, 2001.

[36] C. Bacour, S. Jacquemoud, Y. Tourbier, M. Dechambre, and J.P. Frangi, "Design and analysis of numerical experiments to compare four canopy reflectance models," Remote Sens. Environ., vol. 79, pp. 72-83, 2002.

[37] W. Verhoef, "Earth observation model sensitivity analysis to assess mission performances in terms of geo-biophysical variable retrieval accuracies," In Proc. $9^{\text {th }}$ Int. Symp. Physical Measurements \& Signatures in Remote Sensing, Beijing (China), 17-19 October 2005, pp. 324-327.

[38] P.J. Zarco-Tejada, J.R. Miller, R. Pedrós, W. Verhoef, and M. Berger, "FluorMODgui V3.0: A Graphic User Interface for the spectral simulation of leaf and canopy chlorophyll fluorescence," Computers \& Geosciences, in press. [http://www.ias.csic.es/fluormod/]

[39] S. Jacquemoud, and F. Baret, "Estimating vegetation biophysical parameters by inversion of a reflectance model on high spectral resolution data", in Crop Structure and Ligth Microclimate: Characterization and Applications, C. Varlet-Grancher, R. Bonhomme, and H. Sinoquet, Eds. Versailles: INRA Editions, pp. 339-350, 1993.

[40] S. Jacquemoud, F. Baret, B. Andrieu, F.M. Danson, and K. Jaggard, "Extraction of vegetation biophysical parameters by inversion of the PROSPECT + SAIL model on sugar beet canopy reflectance data Application to TM and AVIRIS sensors," Remote Sens. Environ., vol. 52, pp. 163-172, 1995.

[41] P.J. Zarco-Tejada, J.R. Miller, T.L. Noland, G.H. Mohammed, and P.H. Sampson, "Scaling-up and model inversion methods with narrow-band optical indices for chlorophyll content estimation in closed forest canopies with hyperspectral data," IEEE Trans. Geosci. Remote Sens., vol. 39, pp. 1491-1507, 2001.

[42] S. Jacquemoud, S. Flasse, J. Verdebout, and G. Schmuck, "Comparison of several optimization methods to extract canopy biophysical parameters," in Proc. $6^{\text {th }}$ International Symposium on Physical Measurements and Signatures in Remote Sensing, Val d'Isère (France), 17-21 January 1994, CNES, pp. 291-298, 1994.

[43] C. Bacour et al., "Reliability of the estimation of vegetation characteristics by inversion of three canopy reflectance models on airborne POLDER data," Agronomie, vol. 22, pp. 555-565, 2002.

[44] M. Meroni, R. Colombo, and C. Panigada, "Inversion of a radiative transfer model with hyperspectral observations for LAI mapping in poplar plantations," Remote Sens. Environ., vol. 92, pp. 195-206, 2004.

[45] M. Weiss, F. Baret, R.B. Myneni, A. Pragnère, and Y. Knyazikhin, "Investigation of a model inversion technique to estimate canopy biophysical variables from spectral and directional reflectance data," Agronomie, vol. 20, pp. 3-22, 2000.

[46] B. Combal, F. Baret, and M. Weiss, "Improving canopy variables estimation from remote sensing data by exploiting ancillary information. Case study on sugar beet canopies," Agronomie, vol. 22, pp. 205-215, 2002.

[47] B. Koetz, F. Baret, H. Poilvé, and J. Hill, "Use of coupled canopy structure dynamic and radiative transfer models to estimate biophysical canopy characteristics," Remote Sens. Environ., vol. 95, pp. 115-124, 2005.

[48] M. Weiss, and F. Baret, "Evaluation of canopy biophysical variable retrieval performances from the accumulation of large swath satellite data," Remote Sens. Environ., vol. 70, pp. 293-306, 1999.

[49] C. Bacour et al., "Neural network estimation of LAI, fAPAR, fCover and LAIxCab, from top of canopy MERIS reflectance data: principles and validation," unpublished.

[50] M. Weiss et al., "Validation of neural net techniques to estimate canopy biophysical variables from remote sensing data," Agronomie, vol. 22, pp. 547-553, 2002.

[51] B. Combal et al., "Retrieval of canopy biophysical variables from bidirectional reflectance using prior information to solve the ill-posed inverse problem," Remote Sens. Environ. vol. 84, pp. 1-15, 2002. 